\title{
Research on the Change Rules of Optical Illusion Deceleration Marking Width and Drivers' Heart Rate
}

\author{
Ting Shang ${ }^{1}$, Boming Tang $^{2}$ and Panpan Tao ${ }^{2 *}$ \\ ${ }^{1}$ School of Traffic \& Transportation, Chongqing Jiaotong University, Chongqing, \\ 400074, China \\ ${ }^{2}$ School of Civil Construction, Chongqing Jiaotong University, Chongqing, \\ 400074, China \\ *335304854@qq.com
}

\begin{abstract}
In order to investigate the impact of the optical illusion deceleration marking width on the change of the driver's heart rate, the comb-tooth deceleration marking was employed as an example and fourteen drivers were tested through indoor simulation at the selected width of 20-50 cm. The changing rate of drivers' heart rate was used as an indicator to evaluate the safety and comfort of the width of the optical illusion deceleration marking and then the regression model for the two was established. The results showed that on the road section with the operating speed of $80 \mathrm{~km} \bullet h^{-1}$, the drivers were getting more and more nervous and the absolute value of the changing rate of their heart rate was bigger and bigger with the increase of the marking width. Take the heart beat change rate of $20 \%$ as the threshold value of drivers' tension and the safety and comfort of the width and calculate it based on the logistic regression model, it showed that the most favorable width of the deceleration marking was $42 \mathrm{~cm}$. Under the same condition, the second round of test was conducted at the operating speed of 40-120 km• $h^{-1}$. The drivers' view was narrowed and vision was decreased with the increase of the operating speed, at this time, the drivers got even more nervous and the changing rate of heart rate increased accordingly.
\end{abstract}

Keywords: Traffic Safety, Changing Rate of Heart Rate, Optical Illusion Deceleration Marking, Widths

\section{Introduction}

Up to the end of 2013, the number of the motor vehicles in China had reached to 250 million, which posed a great threat to the road safety. There were more than 200,000 casualties caused by road traffic every year. Research showed that over speed was the main cause of the road traffic. The injury risk of the traffic accident was in direct proportion to the square of the operating speed, and the death risk was to the fourth power $[1,2]$. The current widely-used mandatory speed bumps, such as the rubber deceleration ridge, spike speed bumps, and shock speed humps., could effectively reduce the operating speed, but may abrade the parts of the vehicles, affect the comfortableness of driving, cause noise pollution, and be difficult for future maintenance. Optical illusion deceleration marking could just make up for the above-mentioned defects. It was a kind of marking set up on the basis of optical illusion theory, i.e., it was a marking to remind the drivers to actively slow down before getting close to the dangerous sites through optical illusion and psychological natural response so that safe driving could be assured.

* Corresponding Author 
Since 1980s, the foreign countries had started the research about the optical illusion deceleration marking. With the help of driving simulator, Godley. [3] studied about the transverse speed humps and side comb-tooth deceleration markings on the driveway with gradually narrower space. The result showed that the speed-reduction effect of the former was better than that of the latter at the early stage and the space had no impact on the speed-reduction effect. In view of the fact that the design parameters of the optical illusion deceleration markings in construction sites were determined by experience, Meyer [4] brought up a simulated design method. The slowing effect of the deceleration markings was decided by the response of the majority of the drivers after watching the graphics. Rakha.'s [5] research showed that the optical illusion deceleration markings could slow down the operating speed of the vehicles. Even for the vehicles that the time headway was over 45 , the markings could also reduce the speed. The slowing effect of optical illusion deceleration markings on the main roads was much better than that of on the local roads. The research conducted by Vest. [6] showed that strobe lights and transverse speed humps had the best slowing effect. The latter could slow down the speed by $2.9 \%$ on average, and the slowing effect was even better as the vehicles accelerated the speed. Sections of Belvue, Silver Lake and Meriden in the United States were delimited by optical illusion deceleration markings by Abdoulaye [7]. After five months, the slowing effects contrast experiment was carried out. Through the statistical methods of Ttest, F-test, Z-test., the average speed of the vehicles, the variance and over speed ratio were analyzed, which showed that Belvue had no slowing effect, and $\mathrm{V}_{85}$ increased by $0.2 \%$; Meriden slowed down by $8.2 \%$, and its $\mathrm{V}_{85}$ slowed down by $8.9 \%$, as much as Silver Lake. The research conducted by the Federal Highway Administration in Roland Iowa [8] showed that the average speed on country road E-18 was $40 \mathrm{~km} \cdot \mathrm{h}^{-1}$ before the test. After twelve months when the rafter speed hump was delimited, the speed data showed that $\mathrm{V}_{85}$ reduced by $6 \mathrm{~km} \bullet \mathrm{h}^{-1}$. In Denton's [9] report, the test section was Newbridge roundabout in Scottish Midlothian. After comparing and analyzing the speeds three weeks before and after the road was delimited, it showed that the slowing effect was quite good, and the speed of $\mathrm{V}_{85}$ and the average speed slowed down by $30 \%$ and $23 \%$ respectively.

At present, the research about the optical illusion deceleration marking in China was still in the exploratory stage [10-12].The typical comb-tooth deceleration marking was taken as an example (See Figure 1), the width of which may make the drivers have an illusion of narrower driveway and then become nervous so that some measures would be adopted to slow down. The existing specification did not specify this width [13-18]. In general, the regulations on the width of the driveway and the design of the vehicle profile size in JTG B01-2003 "highway engineering technical standards" was referred to determine the width of each deceleration marking in the study. However, it was difficult to analyze the influence on the drivers exactly. Therefore, this paper selected the combtooth deceleration markings as the object, and established the physiological quantitative indicators of drivers' psychological stress by virtual simulation test and by measuring drivers' heart rate using heart rate meter so as to determine the relationships between drivers' psychological \& physiological reactions and driving behavior and then optimize the design parameters of the width of optical illusion deceleration markings and improve its application. 


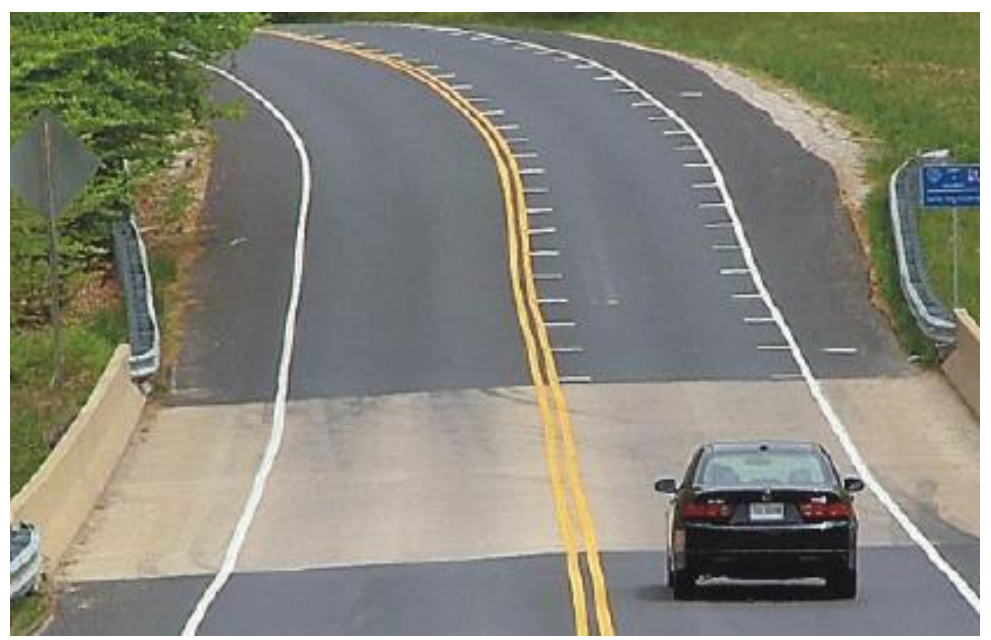

Figure 1. Comb-Tooth Optical Illusion Deceleration Markings

\section{Change Characteristics of Drivers' Tension and Heart Rate}

With the rapid development of traffic psychology, human factors engineering and computer science, the physiological and psychological indexes of human beings were gradually applied in the field of road traffic to reflect the psychological changes of drivers. According to the physiological and psychological research, when the drivers got nervous, their heart rate sped up, breathing quickened, sweating and perspiration increased and face blushed, and accordingly, the vision would be decreased, view be narrowed, pulse sped up and blood pressure elevated.

Currently, the main biological electrical signals that could quantitatively describe the psychological tension of human beings were electrocardiosignal, electroencephalogram, electromyographic signal, respiratory signal, eye signal, skin electrical signal, blood pressure signal. As the brain wave was very weak, it had little impact on the psychological change of the drivers; the skin was easily affected by sweat glands; the drivers was affected by the measurement of electromyographic signal in the process of driving.

Heart rate refers to the number of heat beat in a unit time. It is a technical term that describes the heat beat cycles. The heat rate speed was controlled by the sympathetic nerve and parasympathetic nerve, which coordinated and interacted with each other so that the change of heart rate could be under control. When the body was in a nervous and active state, the sympathetic nerve played a major role to strengthen and accelerate the heat beat, dilate the pupils and increase the capacity of the fatigue muscles. While when the body was relaxed, parasympathetic nerve played a positive role to slow down the heart beat, narrow the pupils and lower the blood pressure [19]. This was physiologic basis of the relationship between mental tension and heart rate. The effectiveness of using heart rate as an index to study the drivers' stress response had been accepted by the scholars [20-22]. Due to the fact that heart rate speed had individual differences, and the changing rate of heart rate was the percentage of the increment of drivers' heart rate (the difference of the heart rate in the process of driving and in the calm state) and the heart rate in the calm state, which could reflect the drivers' state more objectively, this paper, therefore, chose the changing rate of drivers' heart rate as an indicator to evaluate the tension degree of the drivers and analyzed whether the drivers' heart rate change was related to the width of the optical illusion deceleration markings and then tried to analyze its principles. 


\section{Design of Test Program}

In order to avoid the potential risks of the deceleration marking to the drivers, this paper employed indoor simulation test. After the modeling and rendering with 3D MAX software, the video of several simulated straight sections was produced with a width of $3.75 \mathrm{~m}$, and total length of $500 \mathrm{~m}$. The operating speed for the first round of test was set at $80 \mathrm{~km} \cdot \mathrm{h}^{-1}$ and the vision height was $1.5 \mathrm{~m}$, and then comb-tooth deceleration markings of different size of width were added to a section of $300 \mathrm{~m}$. Use dynamic ECG recorder (HOLTER RECORDER MGY-H7, the sampling frequency was $128 \mathrm{~Hz}$ ) to collect the change data of the testers' heart rate when they were watching the video in the humanmachine laboratory. Determine the most suitable width in accordance with the result of the first test, and then proceed with the second round of test at the speed of $40-120 \mathrm{~km}^{\circ} \mathrm{h}^{-1}$.
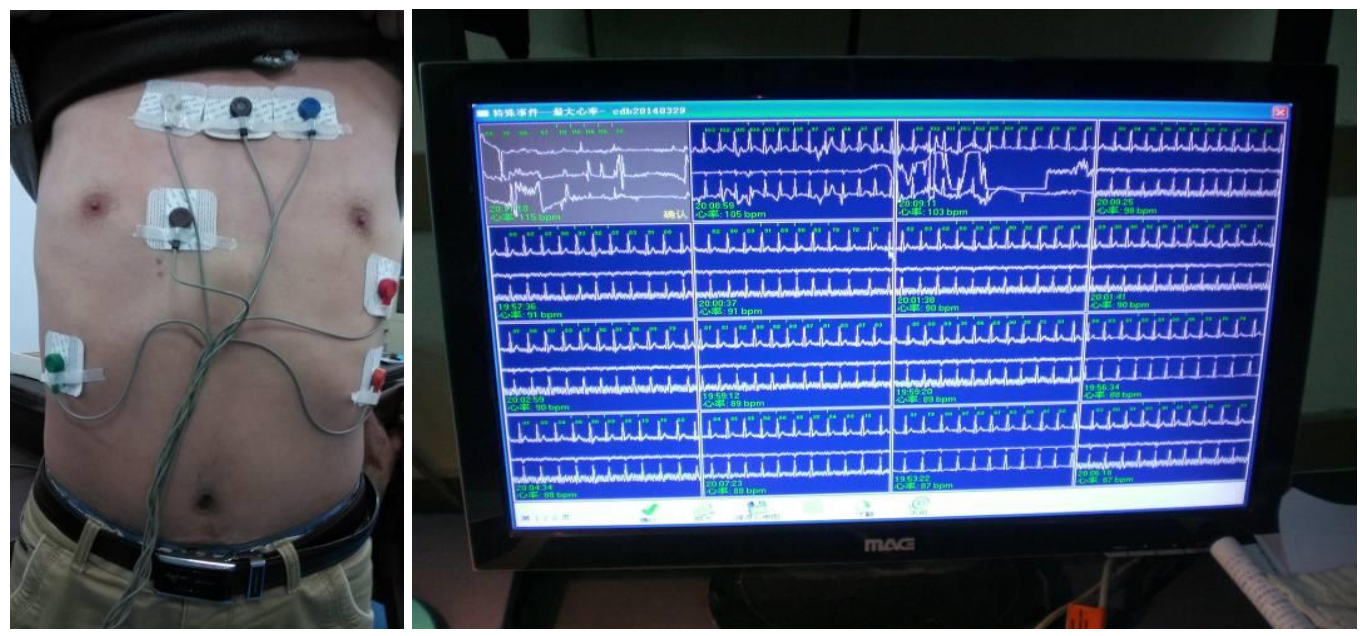

Figure 2. Test Photos

The comb-tooth optical illusion deceleration markings were symmetrically delimited along the two sides of the road, and the design parameters included the width (w), the width of the marking (h) and the distance between two markings (L) as shown in Figure 2. Besides the consideration of drivers' nervous tension caused by the illusion of narrower driveway, how to reduce the rolling, ensure safe driving and make it convenient for construction should also be taken into consideration in determining the width of the markings. According to the existing research results [13-18], it was determined that the width of the comb-tooth deceleration markings (w)was $20 \mathrm{~cm}-50 \mathrm{~cm}$, (h) was $30 \mathrm{~cm}$, and (L)was $5.5 \mathrm{~m}$.

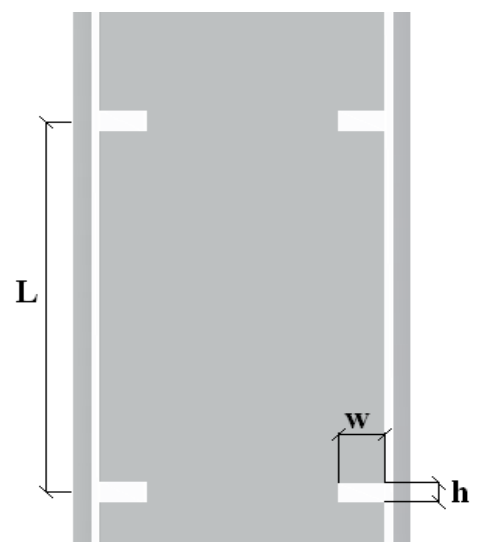

Figure 3. Schematic Diagram of Comb-Tooth Deceleration Markings 
Fourteen drivers with different age and driving experience were chosen for the test as shown in Table 1. Before the test, a preliminary test of the instrument was conducted to check its effectiveness. After correctly wearing the cardiotachometer, collect the testers' resting heart rate in 10 minutes as the normal heart rate, so as to make a comparison with the dynamic heart rate during the test. Start to play the video and record the eye tracker and cardiotachometer at the same time, ensure the data synchronism of all the information and record the starting \& end positions and abnormal situations.

Table 1. Basic Information of the Drivers

\begin{tabular}{|c|c|c|c|c|c|c|c|c|}
\hline \multirow[b]{2}{*}{$\begin{array}{l}\mathrm{N} \\
\mathrm{o} .\end{array}$} & \multirow[b]{2}{*}{$\begin{array}{c}\mathrm{Se} \\
\mathrm{x}\end{array}$} & \multirow[b]{2}{*}{$\mathrm{e}^{\mathrm{Ag}}$} & \multirow{2}{*}{$\begin{array}{l}\text { Drivin } \\
\mathrm{g} \\
\text { Experien } \\
\text { ce }\end{array}$} & \multirow[b]{2}{*}{$\begin{array}{l}\text { Lic } \\
\text { ense } \\
\text { Type }\end{array}$} & & \multicolumn{2}{|c|}{ Eyesight } & \multirow[b]{2}{*}{$\begin{array}{l}\text { Familiarity } \\
\text { with the } \\
\text { Instrument }\end{array}$} \\
\hline & & & & & $\begin{array}{r}\text { Occ } \\
\text { upation }\end{array}$ & $\mathrm{L}$ & $\mathrm{R}$ & \\
\hline 1 & $\mathrm{M}$ & 36 & 5 & $\mathrm{C}$ & $\begin{array}{l}\text { Tea } \\
\text { cher }\end{array}$ & 5.1 & 5.1 & Ordinary \\
\hline 2 & $\mathrm{M}$ & 30 & 3 & B & $\begin{array}{l}\text { Driv } \\
\text { er }\end{array}$ & 5.2 & 5.2 & No \\
\hline 3 & $\mathrm{~F}$ & 46 & 20 & $\mathrm{C}$ & $\begin{array}{l}\text { Driv } \\
\text { er }\end{array}$ & 5.2 & 5.2 & No \\
\hline 4 & $\mathrm{M}$ & 24 & 5 & $\mathrm{C}$ & $\begin{array}{l}\text { Stud } \\
\text { ent }\end{array}$ & 5.1 & 5.2 & Yes \\
\hline 5 & $\mathrm{M}$ & 25 & 1 & $\mathrm{C}$ & $\begin{array}{l}\text { Stud } \\
\text { ent }\end{array}$ & 5.1 & 5.1 & Yes \\
\hline 6 & $\mathrm{M}$ & 50 & 15 & $\mathrm{C}$ & $\begin{array}{l}\text { Tea } \\
\text { cher }\end{array}$ & 5.2 & 5.1 & Ordinary \\
\hline 7 & $\mathrm{M}$ & 30 & 3 & $\mathrm{C}$ & $\begin{array}{l}\text { Tea } \\
\text { cher }\end{array}$ & 5.1 & 5.1 & Yes \\
\hline 8 & $\mathrm{M}$ & 60 & 35 & A & $\begin{array}{l}\text { Driv } \\
\text { er }\end{array}$ & 5.2 & 5.2 & No \\
\hline 9 & $\mathrm{~F}$ & 25 & 3 & $\mathrm{C}$ & $\begin{array}{l}\text { Stud } \\
\text { ent }\end{array}$ & 5.2 & 5.0 & Yes \\
\hline $0^{1}$ & $\mathrm{M}$ & 22 & 1 & $\mathrm{C}$ & $\begin{array}{l}\text { Stud } \\
\text { ent }\end{array}$ & 5.0 & 5.1 & No \\
\hline${ }_{1}^{1}$ & $\mathrm{M}$ & 30 & 8 & $\mathrm{C}$ & $\begin{array}{l}\text { Stud } \\
\text { ent }\end{array}$ & 5.1 & 5.1 & Yes \\
\hline $2^{1}$ & $\mathrm{M}$ & 19 & 1 & $\mathrm{C}$ & $\begin{array}{l}\text { Tea } \\
\text { cher }\end{array}$ & 5.1 & 5.0 & Yes \\
\hline $3^{1}$ & $\mathrm{~F}$ & 35 & 7 & $\mathrm{C}$ & $\begin{array}{l}\text { Stud } \\
\text { ent }\end{array}$ & 5.0 & 5.0 & Ordinary \\
\hline $4^{1}$ & $\mathrm{M}$ & 42 & 10 & B & $\begin{array}{l}\text { Driv } \\
\text { er }\end{array}$ & 5.2 & 5.2 & No \\
\hline
\end{tabular}

\section{Test Results Analysis}

\subsection{Test Data Processing and Analysis}

Electrocardiosignal was random signal, so that high-pass filter processing needed to be made in order to eliminate the abnormal data. Observe the original data with the built-in analysis program of cardiotachometer, and then use SPSS software for further analysis. Figure 4 was the changing rate of drivers' heart rate at the operating speed of $80 \mathrm{~km} \bullet \mathrm{h}-1$ and the width of the markings $20,35,50 \mathrm{~cm}$ respectively. 


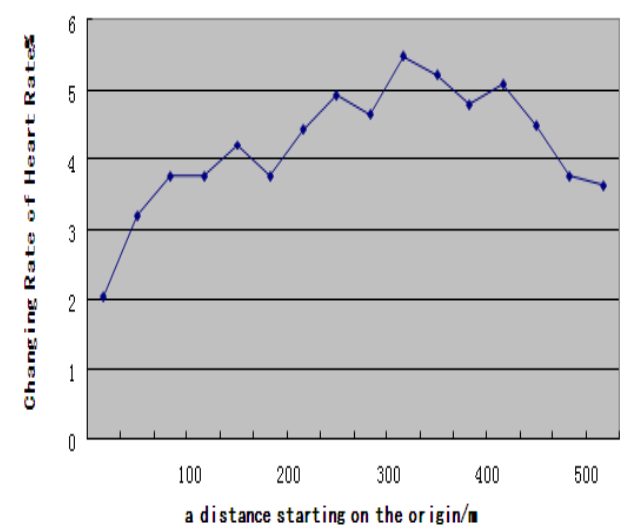

(A) When (W) Was $20 \mathrm{~cm}$

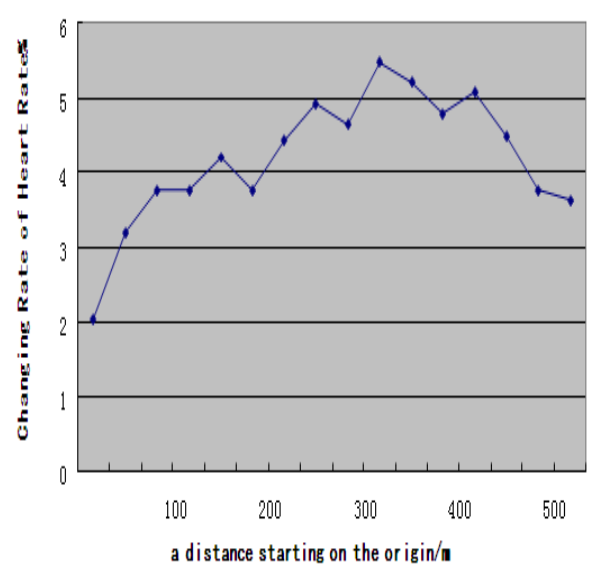

(B) When (W) Was $35 \mathrm{Cm}$

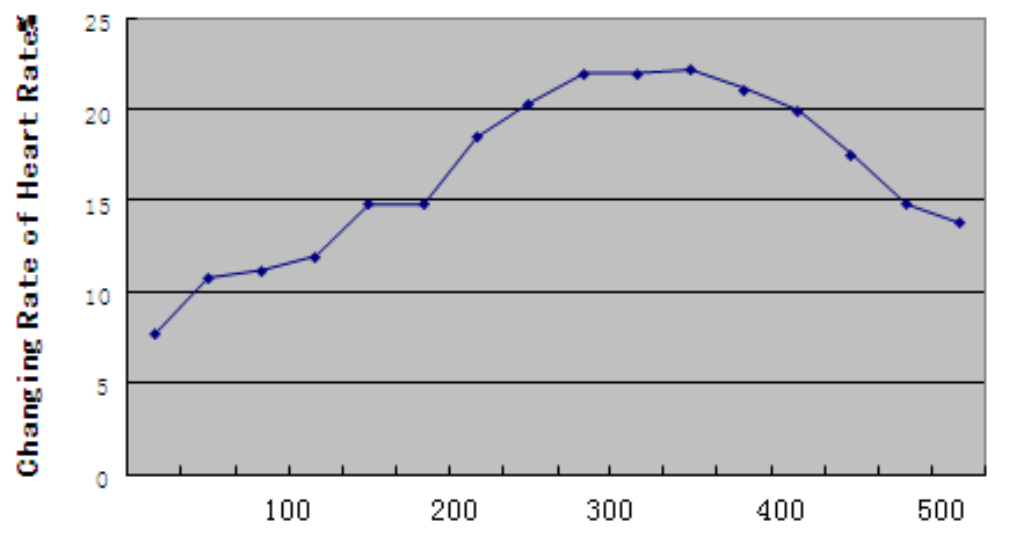

a distance starting on the or igin/m

(C) When (W) Was $50 \mathrm{Cm}$

\section{Figure 4. Changing Rate of Heart Rate with Different Width}

The traffic environment and road alignment directly affected drivers' driving behavior and psychological stress, so in the process of simulation video production, overtaking, driveway changing, steep slopes, sharp turns and tunnels were not taken into consideration. Figure 4 showed the changing rate of the drivers' heart rate when they drove into the optical illusion deceleration markings in the free flow state at the operating speed of $80 \mathrm{~km} \bullet \mathrm{h}-1$. At the beginning of the video, the changing rate of the drivers' heart rate was basically stable before they got close to the comb-tooth deceleration markings; when they almost got close, they could see some white transverse markings ahead while could not make sure, so they would get a little nervous and the heart rate increased in different degrees; when they drove into the markings, they may have an illusion that the driveway got narrower, at this time, they would be more focused and drive more carefully, and also get more nervous so the changing rate of their heart rate was much greater, the range ability of which was even more than $20 \%$; when they drove away from the markings, the nervous tension gradually faded, and the changing rate of the heart rate would become stable again. On the same road alignment and at the same operating speed, the wider the comb-tooth deceleration marking was; the more nervous the drivers were and the bigger the changing rate of their heart rate was. 
From the above analysis, it can be concluded that the drivers may get nervous and the changing rate of their heart rate increased if comb-tooth deceleration markings were delimited along the road.

\subsection{Mathematical Modeling}

(1) The relationship between the width of the marking and the changing rate of heart rate

From the analysis of the drivers' driving characteristics at the comb-tooth deceleration markings, it showed that the change of the heart rate may be related with the width of the markings in different degrees. In order to avoid the drivers' unfit mood when they just saw the markings and the nervous tension after they drove away from the markings, the middle section of the deceleration markings was chosen as the sample to establish the regression model of the width and the changing rate of drivers' heart rate based on the regression analysis theory and method [23, 24].

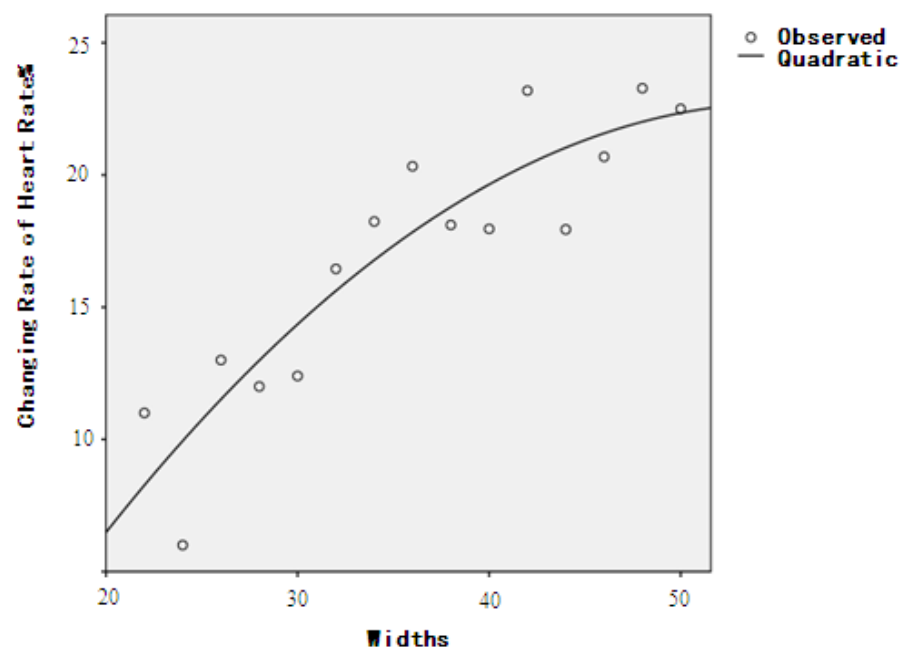

\section{Figure 5.The Relationship between the Width of the Marking and the Changing Rate of Heart Rate}

According to the regression line, the regression model for the width of the markings (W) and the changing rate of drivers' heart rate (U) was as follows:

$$
\mathrm{U}=-0.013 \mathrm{~W}^{2}+1.433 \mathrm{~W}-17.012
$$

In formula (1), the fit test for the regression model $\mathrm{R} 2$ was 0.826 , which indicated that this width had very good linear relationship with the change of drivers' heart rate.

According to the scatter diagram of the width and the changing rate of the heart rate based on the experimental data as shown in Figure 5, when the drivers got close to the comb-tooth deceleration marking section at the operating speed of $80 \mathrm{~km} \bullet \mathrm{h}-1$, it was more likely that they had the illusion of narrower driveway as the increase of the width and at the same time their tension got stronger and heart rate increased. This was consistent with the theoretical basis of "heart rate increases when tension, while reduces when fatigue". Therefore, the width and the changing rate of heart rate formed a quadratic linear relationship. The application range of the model was: $\mathrm{W} \in[20,50]$.

The research from both at home and abroad showed that ${ }^{[25]}$ when the drivers' heart rate exceeded $20 \%$ of the normal heart rate in the process of driving, they would get nervous, and when it exceeded $40 \%$, they would be overloaded and accidents may happen. Take the heart beat change rate of $20 \%$ as the threshold value of drivers' tension and the safety 
and comfort of the pavement and calculate it by Formula (1). When the operating speed was $80 \mathrm{~km} \cdot \mathrm{h}-1$ and the width of the marking was $41.9 \mathrm{~cm}$, the best slowing effect could be achieved while safety of driving was guaranteed at the same time. For easier construction, the recommended value was $42 \mathrm{~cm}$.

(2) The relationship between operating speed and the changing rate of heart rate

From the first round of test, the width of $42 \mathrm{~cm}$ was the most favorable one. Then proceed with the second round of test at the operating speed of $40-120 \mathrm{~km} \cdot \mathrm{h}-1$ so as to find out the rules of the changing rate of drivers' heart rate (as shown in Table 2) at different operating speeds, and establish the regression model for the operating speed and heart beat change rate on the basis of regression analysis theory and method.

Table 2. Experimental Data

\begin{tabular}{cccc}
\hline No. & Marking Width/cm & Speed $/ \mathrm{km} \cdot \mathrm{h}^{-1}$ & $\begin{array}{c}\text { Changing Rate of Heart } \\
\text { Rate/\% }\end{array}$ \\
\hline 1 & 42 & 40 & 6.51 \\
2 & 42 & 45 & 9.89 \\
3 & 42 & 50 & 8.71 \\
4 & 42 & 55 & 20.42 \\
5 & 42 & 60 & 12.22 \\
6 & 42 & 65 & 10.4 \\
7 & 42 & 70 & 16.45 \\
8 & 42 & 75 & 16.72 \\
9 & 42 & 80 & 20.5 \\
10 & 42 & 85 & 16.33 \\
11 & 42 & 90 & 19.45 \\
12 & 42 & 95 & 15.89 \\
13 & 42 & 100 & 17.34 \\
14 & 42 & 105 & 24.69 \\
15 & 42 & 110 & 23.68 \\
16 & 42 & 115 & 22.92 \\
17 & 42 & 120 & 29.32 \\
\hline
\end{tabular}

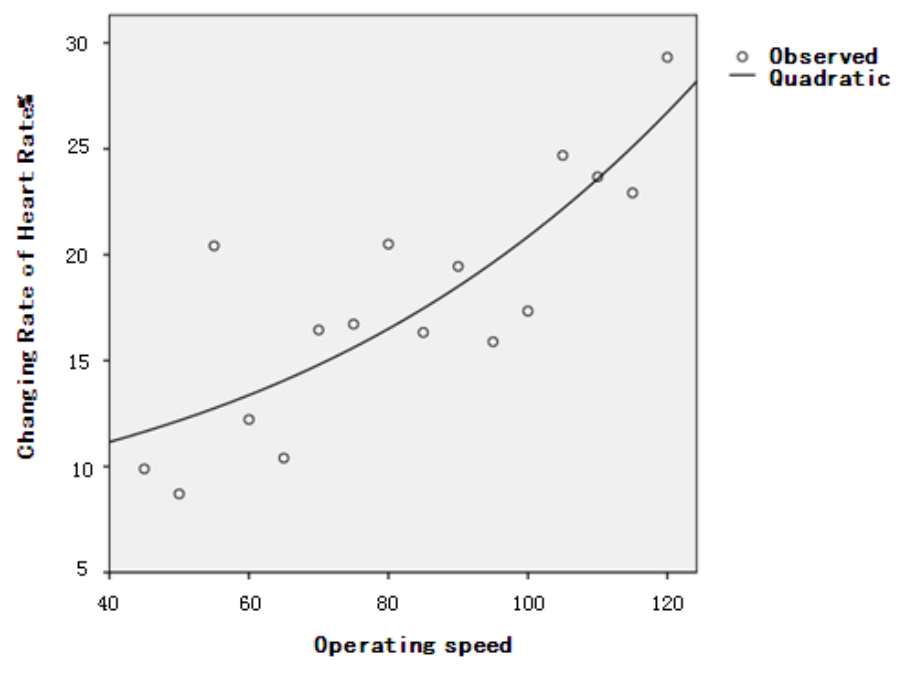

Figure 6. The Relationship between Operating Speed and the Changing Rate of Heart Rate

According to the regression line, the regression model for the operating speed (V) and the changing rate of drivers' heart rate (U) was as follows: 


$$
\mathrm{U}=6.365 \mathrm{E}-6 \mathrm{~V}^{3}+0.062 \mathrm{~V}+8.263
$$

In formula (2), the fit test for the regression model $\mathrm{R} 2$ was 0.689 , which indicated that there was fairly good positive correlation between the operating speed and the changing rate of drivers' heart rate.

According to the scatter diagram of the operating speed and the changing rate of the heart rate based on the experimental data as shown in Figure 6, when the width was $42 \mathrm{~cm}$, the drivers' view was narrowed and vision was decreased as the increase of the operating speed, at this time, they got more nervous and the changing rate of their heart rate got bigger so they would pay more attention to the markings on the pavement. There formed a linear relationship between the operating speed and heart beat change rate.

\section{Conclusions}

(1) When the drivers drove into the comb-tooth deceleration marking section, there were logical relations between the changing rate of the drivers' heart rate and the width of the marking and the operating speed. The quantitative relationship model between them was thereby established.

(2) According to the quantitative model, when the operating speed was $80 \mathrm{~km} \cdot \mathrm{h}-1$, and the changing rate of $20 \%$ was taken as the threshold value that the drivers would get nervous in the free flow on the flat section, the corresponding width of the deceleration marking was $42 \mathrm{~cm}$.

(3) This paper was limited to the research on the width of the marking at the operating speed of $80 \mathrm{~km} \cdot \mathrm{h}-1$, and the rules of the heart beat change rate with the most favorable width at different operating speeds. However, both of them had some limitations. As for the research about the marking width at other design speed or under speed-limit condition and the changing rate of drivers' heart rate at different speeds, the same theory and methods need to be employed for further experiment.

\section{References}

[1] Z. Wang, "Traffic Injury Research of the 21st Century", Journal of Traumatic Surgery, vol. 2, no. 2, (2000).

[2] Z. Wang, "The 15th International Accidents and Traffic Medical Conference and Overview of Dangerous Behavior and Traffic Safety International Conference", Chinese Journal of Traumatology, vol. 14 , no. 15 , (1998).

[3] S. Godley, "A Driving Simulator Investigation of Perceptual Countermeasures to Speeding", Department of Psychology, Monash University, (1999).

[4] E. Meyer, “A New Look at Optical Speed Bars”, ITE Journal, vol. 71, no.11, (2001).

[5] H. Rakha, K. Ahmed, J. Bryan J and D. Duke, "Design and Evaluation of Peripheral Transverse Bars to Reduce Vehicle Speed", TRB $85^{\text {th }}$ Annual Meeting Compendium of Papers CD-ROM.Washington, DC, (2006).

[6] A. Vest and N. Stamatiadis, "Use of Warning Signs and Markings to Reduce Speeds on Curves", TRB $84^{\text {th }}$ Annual Meeting. Washington, DC, (2005).

[7] A.D. Balde, "Speed Management in rural communities using optical speed bars", KANSAS State University, no. 105-109, (2010).

[8] R. Krammes, "Traffic Calming on Main Roads Through Rural Communities",Federal Highway Administration, no. 7-8, (2009).

[9] J.N.Y. Wei, H.S. Tim and C., S. handrasekar S and O. Palanisamy, "An Assessment on the Effectiveness of Traffic Calming Marking and Alternative for Speed Regulating Strips", 16th Road Safety on Four Continents Conference, Beijing, vol.15, no. 2, (2013).

[10] M.O. Qiuyun and L.I. Rongjing, "Research about Driver's Physiological Characteristics under Mountain Road Conditions", Electronic Science and Technology, vol. 2, no. 83, (2013).

[11] S. Fan, "Course of Traffic Psychology",Chinese People's Public Security University Press, Beijing, (2005).

[12] X. Pan, "The Application of Human Body Information Technology in Safety Evaluation of Road Geometry Structure", School of Transportation Engineering, Tongji University, (2002).

[13] S. Zhu and Z. Zhang, "Relationship Between Highway Edge Rate Marking Time Frequency \& Angle and Slowing Effect", China Journal of Highway, vol. 3, no. 87-89, (2014). 
[14] X. Yan, "Design Research about Optical Illusion Deceleration Marking”, Changan University, (2011).

[15] H. Liu, J. Liu and W. ZHAO, "Parameters Optimization of Optical Illusion Deceleration Marking", Journal of Chang' an University(Natural Science Edition), vol. 31, no. 78, (2011).

[16] J. Wu, Y. Yan and X. Liu, "Design Optimization Study about Optical Illusion Deceleration Marking", Journal of China \& Foreign Highway, vol. 32, no. 301-302.

[17] F. Galantea, F. Maurielloa and A. Montella, "Traffic calming along rural highways crossing small urban communities: Driving simulator experiment”, Accident Analysis and Prevention, vol. 42, no. 1588, (2010).

[18] F. Zheng, "Design and Applied Research about Road Speed Facilities", Jilin University, (2008).

[19] Y. Li, G. Yin and Y. Chen, "The Regulating Effect of Fatigue and Mental Load on Pupil Size in Reading", Studies of Psychology and Behavior , vol. 2, no. 545-548, (2004).

[20] S.D.M. Bot, A.P. Hollander, "The relationship between heart rate and oxygen uptake during nonsteady state exercise", ERGONOMICS, vol. 43, no. 581-592, (2000).

[21] M. Chang, J. Kim and K. Kang, "Evaluation of driver's psycho physiological load at freeway merging area", TRB, no 129-133, (2001).

[22] F. Tomoki, J. Masato and T. Kadoma, "Drivers'behavior in S curve negotiations on an urban motorway", Traffic and Transport.Studies Proc. of ICTTS, vol. 2, no. 849-856, (2002).

[23] J. Wang, "Test Design and the Application of SPSS",Chemical Industry Press, Beijing, (2007).

[24] H. Li, "Statistical Analysis Software and Application Experiments", Economic Science Press, Beijing, (2008).

[25] Q. Luo, “Japan:Railway Research Report”, (1995).

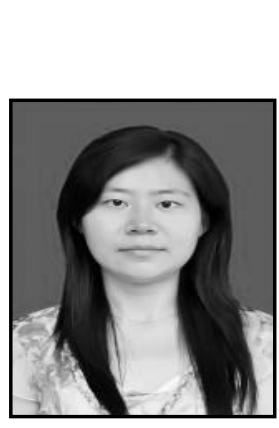

\section{Authors}

Ting Shang, she received her M.S degree in Highway Engineering from Chongqing Jiaotong University, China in 2009. Currently she is a $\mathrm{Ph}$. D. student in Transportation Engineering from Chongqing Jiaotong University. Her research interests are Road Traffic Security, Cognitive Psychology, Human Factor Engineering.

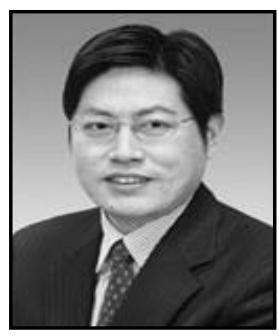

Boming Tang, he works at Chongqing Jiaotong University in China. He received B.S. degree from Southeast University in 1985, M.S. degree from Southeast University of Roads and Traffic Engineering in 1987 and Ph.D. degree from Southeast University in 1990. His research interests include Road Traffic Security, Traffic Engineering and Human Factor Engineering.

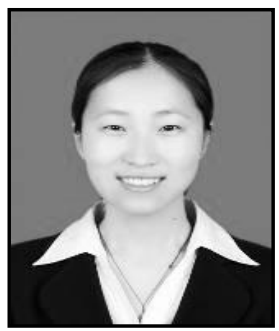

Panpan Tao, she received her B.E degree in Road Bridge and River-crossing Engineering from Shandong Agriculture University,China in 2013. Currently she is a Postgraduate student in Transportation Engineering from Chongqing Jiaotong University. Her research interests are Road Traffic Security, Traffic Psychology. 